\title{
CONTRIBUIÇÃO À ORGANIZAÇÃO DE SERVIÇOS DE TRANSPLANTE DE MEDULA ÓSSEA E A ATUAÇÃO DO ENFERMEIRO*
}

\author{
Sueli Riul ** \\ Olga Maimoni Aguillar ***
}

RIUL, S.; AGUILLAR, O.M. Contribuição à organização de serviços de transplante de medula óssea e a atuação do enfermeiro. Rev.latino-am.enfermagem, Ribeirão Preto, v. 5, n. 1, p. 49-58, janeiro 1997.

Trata-se de um estudo bibliográfico sobre a temática: transplante de medula óssea com ênfase na atuação do enfermeiro, levantada em publicações de enfermagem dos últimos dez anos. As informações, organizadas e sintetizadas permitiram identificar que para a realização do transplante são necessários uma infra-estrutura apropriada, recursos humanos especializados e recursos operacionais que viabilizem a assistência. Foi possível identificar também que a atuação do enfermeiro nesse procedimento se dá em todas as fases do processo de assistência ao paciente, de modo peculiar em cada uma delas, preferentemente de forma individualizada e integral, na proporção máxima de um enfermeiro para dois pacientes.

UNITERMOS: transplante de medula óssea, assistência de enfermagem

\section{APRESENTAÇÃO}

O presente trabalho teve início a partir da nossa participação na implementação de um serviço de transplante de medula óssea, num hospital geral de grande porte do interior paulista, enquanto enfermeira assistencial de centro cirúrgico.

Naquele momento fomos chamadas a organizar a atuação da equipe de enfermagem para o atendimento aos pacientes submetidos a transplante de medula óssea (TMO) ainda no centro cirúrgico.

Ao aprofundarmos nossos estudos sobre o assunto, tomamos conhecimento de que o tratamento baseado no TMO é bastante complexo e requer uma assistência de enfermagem especializada, uma vez que ao longo desse tratamento o paciente necessita de cuidados de enfermagem específicos para superar o comprometimento orgânico decorrente do tratamento.

Considerando a complexidade da assistência de que este paciente necessita e dando continuidade a nossos estudos, procuramos trazer da literatura subsídios que nos ajudassem a responder questões relacionadas aos requisitos para implementação de serviços de TMO e a assistência de enfermagem adequada ao paciente submetido a este tratamento.
Hoje no Brasil, é realizada uma média de 100 desses procedimentos anualmente, oferecendo 0 tratamento com modernas e avançadas tecnologias médicas. Constantes avanços científicos na área e a implementação de novos serviços de transplante de medula óssea nos fizeram acreditar na necessidade de investir na elaboração de um conjunto de atividades e cuidados sistematizados de enfermagem que respondessem às necessidades do paciente $\mathrm{e}$ ainda, adequando a essas necessidades os requisitos do serviço.

\section{REVISÃO DA LITERATURA}

\section{Conceituação do transplante de medula óssea}

O transplante de medula óssea (TMO)
segundo PASQUINI \& FERREIRA, é um
procedimento terapêutico que consiste na infusão
por via intravenosa, de sangue de medula óssea
obtido de um doador, previamente selecionado, em
um receptor adequadamente condicionado. A sua
finalidade é reconstruir o órgão hematopoiético
enfermo, devido a sua destruição, como nos
casos de aplasia, ou devido à proliferação celular

\footnotetext{
* Resumo de dissertação apresentada à Escola de Enfermagem de Ribeirão Preto da Universidade de São Paulo, para obtenção do grau de mestre

** Professora Auxiliar de Ensino do Departamento de Enfermagem na Assistência Hospitalar do Centro de Graduação em Enfermagem da F.M.T.M.

*** Professora Doutora do Departamento de Enfermagem Geral e Especializada da Escola de Enfermagem de Ribeirão Preto da Universidade de São Paulo
} 
neoplástica, como nos casos de leucemia. Além dessas enfermidades, outras também tem sido objeto dessa modalidade de tratamento.

DULLEY et al ${ }^{3}$ dizem que o tratamento consiste de intensa imunossupressão do paciente com altas doses de quimioterapia (QT) associadas ou ao uso de irradiação corporal total (ICT). O resgate do sistema hematopoiético é feito através da infusão de medula óssea de um doador previamente selecionado através da tipagem dos antígenos leucocitários humanos (HLA - Human Leukocyte Antigens) e da cultura mista de leucócitos (CML). O procedimento compreende a retirada parcial de medula óssea, através de múltiplas aspirações da crista ilíaca da cintura pélvica do doador, filtragem da medula óssea e transferência para bolsas de transfusão sem anticoagulante.

O paciente então, recebe o transplante através da infusão intravenosa da medula óssea assim coletada e essas células irão circular na corrente sanguínea sendo que parte delas se implantarão no microambiente medular, iniciando o processo de repopulação medular e reconstituição hematopoética ${ }^{3}$.

\section{Tratamento com transplante de medula óssea}

Atualmente, são consideradas doenças tratáveis com TMO, as doenças adquiridas e congênitas, de caráter maligno ou não, conforme se segue ${ }^{1,2,3,4}$.

a) Adquiridas

- de caráter maligno: como as leucemias, a doença de Hodgkin e tumores sólidos;

- de caráter não maligno: como a anemia aplástica;

b) Congênitas

- imunodeficiências

- defeitos hematológicos.

\section{Tipos de TMO}

A fonte de medula óssea usada determina o "tipo" de transplante que o paciente recebe ${ }^{1,2}$.

- TMO autólogo: é aquele onde se usa a própria medula da paciente, colhida em um momento oportuno, logo criopreservada e re-infundida no paciente, após o tratamento específico da doença de base;

- TMO singênico: é aquele realizado entre gêmeos idênticos, onde existe perfeita identidade entre ambos sistemas HLA;

- TMO alogênico: é aquele que envolve enxertamento entre um doador e um receptor de origem genética diferente, dentro da mesma espécie, geralmente um irmão HLA idêntico.

\section{Seleção do doador}

São apontados como doadores de medula óssea em potencial, o próprio paciente, um irmão gêmeo monozigótico, um doador relacionado familiarmente ou não com o paciente ${ }^{1,2}$.

\section{Procedimento do transplante de medula óssea}

\section{1 - Preparação pré-transplante}

a) Período pré-admissional

Os pacientes são encaminhados a um serviço de transplante de medula pelo serviço de saúde de sua comunidade entram em contato com a equipe de TMO, quando se procede a maiores esclarecimentos $\mathrm{e}$ detalhes sobre o tratamento, cuidados médicos e preparo psico-sicial $^{1,2}$.

b) Avaliação médica

Uma avaliação médica completa do paciente deve incluir: história médica completa, estudo do estágio do tumor para doenças malignas, história pertinente para proteção contra toxidade de órgãos, teste de histocompatibilidade para transplante de medula alogênico e singênico, planejamento de suporte transfusional, avaliação médica completa do doador ${ }^{1,2}$.

c) Admissão hospitalar do paciente e preparo prétransplante

O preparo pré-transplante consiste fundamentalmente na implementação de medidas protetoras que visem prevenir infecções oportunistas durante a imunossupressão e no implante de um cateter atrial direito de longa permanência (tipo HICKMANBROVIAC) para acesso contínuo ao sistema circulatório do paciente ${ }^{1,2}$.

d) Regime de condicionamento

Dias antes da infusão da medula óssea, os pacientes são submetidos a doses intensivas de quimioterápicos, muito às vezes acrescidos de irradiação corporal total. Este tratamento é conhecido como regime condicionante (ou preparativo) e freqüentemente assume um caráter mieloablativo ${ }^{1,2}$.

O condicionamento tem geralmente duas finalidades: imunossupressão e remoção de células não desejáveis, (embora benignas) ${ }^{1,2}$.

A partir do início do regime condicionante, os dias são contados regressivamente até seu término, geralmente a partir do dia - 10, seguindo-se a infusão da medula óssea no dia seguinte, dia considerado zero do tratamento ${ }^{1,2}$. (Ver representação esquemática do processo de TMO, anexo 1)

2 - Aspiração, processamento e infusão de medula óssea a) Aspiração de medula óssea

O procedimento da coleta de medula óssea é realizado em condições assépticas numa sala de operações de centro cirúrgico. Sua duração é de uma a duas horas e o doador é geralmente submetido a anestesia geral $^{1,2}$.

O local de aspiração de medula é geralmente a 
crista ilíaca posterior; contudo, se uma quantidade maior de medula é necessária à crista ilíaca anterior também pode ser aspirada bem como o osso externo e a tíbia ${ }^{1,2}$.

Através de punções na pelve e no osso pélvico, realizadas com agulhas de seis a dez centímetros de comprimento, realizam-se cinco a dez aspirações num único ponto, aspirando-se de três a cinco $\mathrm{ml}$ de medula em cada aspiração. A medula é coletada em recipientes de 1000 a $2000 \mathrm{ml}$ de capacidade e é diluída em um meio conservante composto de aminoácidos, glicose e heparina ${ }^{1,2}$.

São necessários 150 a 300 aspirações para se obter o número de células nucleadas necessárias. Completada a aspiração a medula óssea é filtrada através de duas finas telas de aço inoxidável, o que elimina do aspirado partículas de gordura e espículas ósseas ${ }^{1,2}$.

A medula óssea é então acondicionada em bolsas coletoras de sangue sem conservantes, para imediata infusão endovenosa no receptor, ou para processamento futuro e estocagem apropriada ${ }^{1,2}$.

b) Processamento da medula óssea

Se a medula óssea não for imediatamente infundida no receptor, pode ser acondicionada, sem tratamento especial a $-4^{\circ} \mathrm{C}$ por até 48 horas. Caso seja necessária sua estocagem por tempo maior, a medula óssea deve ser crio-preservada por método de congelamento especial, podendo assim permanecer por tempo indeterminado ${ }^{1,2}$.

Em casos especiais a medula óssea pode ser manipulada. Dessa forma pode sofrer: depleção de plasma para remoção de isoaglutininas, depleção de linfócitos - T, purificação de células tumorais ${ }^{2}$.

c) Infusão de medula óssea

O grande calibre do cateter venoso central permite que a infusão seja realizada aproximadamente num intervalo de uma a seis horas"

3 - Enxertamento da medula óssea

O sinal de enxertamento ("pega" da medula óssea é a expressão comumente utilizada) é o desenvolvimento normal de eritrócitos, leucócitos e plaquetas na medula. Estes sinais geralmente aparecem em torno do $14^{\circ}$ dia após o transplante. A diferenciação das células brancas do sangue é outro sinal indicador de enxertamento, com o aumento de polímorfonucleares ou granulócitos maduros que mostram o funcionamento normal da medula ${ }^{1 .}$

O enxertamento pode ser definido pela análise do padrão cromossômico de células do sangue que caracterize o doador ou o receptor ${ }^{1}$.

4 - Alta hospitalar do paciente e acompanhamento ambulatorial

Quando há sinais evidentes de sucesso do enxertamento da medula óssea e estão superadas as complicações agudas do transplante, o paciente pode ser liberado do hospital, porém deve continuar sendo acompanhado ambulatorialmente para detecção e tratamento de complicações crônicas ${ }^{1}$.

\section{Complicações no transplante de medula óssea}

As complicações no TMO podem ser classificadas em agudas e crônicas sendo as agudas aquelas que ocorrem desde o início do regime de condicionamento, ou seja, do dia -10 do tratamento, até aproximadamente o dia +100 após o transplante. As complicações crônicas são aquelas que ocorrem a partir do dia +100 após o transplante ${ }^{1,2}$.

1 - Agudas ${ }^{1,2}$

a) Efeitos colaterais do regime de condicionamento: náusea e vômito, diarréia, mucosite, cistite hemorrágica, pancitopenia, lesões hepáticas, insuficiência renal aguda, neurotoxicidade, pneumonite intersticial, desequilíbrio hidro-eletrolítico, reações dermatológicas, alopecia.

b) Doença Enxerto Versus Hospedeira (DEVH) aguda: complicação específica do TMO alogênico, que se explica pelo fato do receptor, estando incapaz de desenvolver qualquer resposta imune, não ter possibilidade de rejeitar o enxerto recebido. Por outro lado, o que se está transplantando são células imunocompetentes, sendo assim, não é o receptor quem rejeita o enxerto, e sim o enxerto que rejeita o receptor.

Clinicamente, a DEVH manifesta-se geralmente de duas a oito semanas após o transplante e suas manifestações incluem náuseas e vômitos, desconfortos gastrointestinais, lesões hepáticas, exantema maculopapular.

c) Falência da medula óssea enxertada e rejeição

A falência no enxertamento de medula óssea pode ocorrer em alguns casos e se define pela persistência de células progenitoras hematopoiéticas do doador no receptor, sem que haja, contudo, uma função medular eficiente. A rejeição da medula óssea é a perda das células do doador e o retorno das células enfermas. d) Infecções

Em pacientes submetidos a TMO, diferentes tipos de infecções tendem a ocorrer, mais ou menos especificamente, segundo a fase do tratamento em que este paciente se encontre, e isto se deve às variações no sistema imunológico que acompanham estas fases.

2 - Crônicas ${ }^{1,2}$

a) DEVH crônica

Geralmente se desenvolve três meses após o transplante. A maioria dos pacientes que desenvolvem a forma aguda desenvolve também a crônica. Apresenta-se numa forma sub-clínica, limitada ou extensiva, e suas manifestações são dermatológicas, hepáticas, gastrointestinais, oftálmicas, pulmonar.

b) Problemas pulmonares

São geralmente conseqüentes ao regime de 
condicionamento ou a DEVH. São: pneumonite intersticial, doença pulmonar restritiva, doença pulmonar obstrutiva crônica, bronquite linfocítica, bronquiolite obliterante.

e) Complicações neuro-endócrinas, do crescimento e desenvolvimento

São conseqüências principalmente do regime de condicionamento. Manifestam-se, sobretudo por hipo ou hipertireoidismo, insuficiência adrenal, crescimento e desenvolvimento sexual retardado em TMO infantil, infertilidade, andropausa e menopausa precoce.

d) Entidades mórbidas de caráter maligno secundárias ao TMO

Doenças malignas podem decorrer do uso de agentes citotóxicos, radiação ionizante e drogas imunossupressivas, todos eles sabidamente oncogênicos.

\section{OBJETIVOS}

O presente trabalho tem por objetivo descrever a organização de um serviço de transplante de medula óssea considerando a infra-estrutura, os recursos humanos e operacionais e a atuação do enfermeiro, utilizando os seguintes passos:

1 - levantar a literatura científica em nível nacional e internacional, nos últimos dez anos, que aborde a temática: assistência de enfermagem ao paciente adulto submetido a transplante de medula óssea;

2 - organizar os conteúdos da literatura levantada e apresentar uma síntese dos principais aspectos encontrados dentro da temática que possam subsidiar:

- a implementação de serviços de enfermagem em transplante de medula óssea;

- a atuação do enfermeiro com vistas à assistência de enfermagem ao paciente adulto submetido a TMO.

\section{METODOLOGIA}

De acordo com nosso objetivo, utilizamos os seguintes passos para a de nossa pesquisa:

1 - Identificação das fontes bibliográficas

Realizada através da seção de automação da Biblioteca Central - Campus de Ribeirão Preto, pelo Sistema Integrado de Bibliotecas da Universidade de São Paulo. Os unitermos utilizados foram: transplante de medula óssea - assistência de enfermagem ("bone marrow transplantation" - "nursing care").

A seguintes fontes bibliográficas foram selecionadas: Comprehensive Medline, Lilacs, Dedalus, Publicações de Enfermagem no Brasil.

O levantamento bibliográfico a partir das referidas fontes foi feito desde 1984 até 1994.

\section{2 - Localização das publicações}

Realizada pela consulta aos fichários da Biblioteca Central - Campus de Ribeirão Preto - USP e do Serviço de Comutação Bibliográfica (COMUT).

A obtenção do material foi feita através de empréstimo, consulta privativa e pelo sistema de reprodução de cópias.

\section{3 - Leitura do material}

De posse do material bibliográfico iniciamos uma fase de leitura exploratória com a finalidade de determinar o material que de fato interessasse à pesquisa respondendo a questão: qual a assistência adequada ao paciente adulto submetido a TMO?

A leitura do material foi orientada pelas seguintes diretrizes: identificação das informações e dos dados constantes do material impresso, estabelecimento de relações entre as informações e os dados obtidos com o problema proposto e análise da consistência das informações e dados apresentados pelos autores.

A seguir procedemos a uma leitura analítica dos textos selecionados com a finalidade de ordenar e sumarizar as informações neles contidas.

Feito isto, organizamos estas idéias seguindo uma ordem de importância, distinguindo aquelas principais das secundárias e ainda segundo as fases do tratamento baseado em TMO para uma síntese posterior.

4-Síntese sistematizada da organização de um serviço de TMO e da atuação do enfermeiro neste procedimento

Após a leitura analítica da literatura nos propusemos a sistematizar as propostas de assistência ao paciente adulto submetido a TMO relacionando-as com as fases do tratamento e apontando os aspectos convergentes e conflitantes das mesmas e numa última fase, sintetizar essas propostas descrevendo a assistência de forma que pudessem subsidiar a implementação de serviços nesta área.

Contudo, outros aspectos encontrados no material bibliográficos pesquisado e igualmente relevantes, também foram por nós trazidos a este estudo, uma vez que dentro deste material foi identificada grande convergência entre as idéias dos autores na descrição da temática abordada.

\section{SÍNTESE}

Considerando os aspectos convergentes que predominaram na revisão da literatura por nós pesquisada, passamos a apresentar uma síntese dos principais pontos encontrados a respeito da infraestrutura, recursos humanos e operacionais necessários à realização do $\mathrm{TMO}$, bem como da atuação do enfermeiro nesse procedimento terapêutico. 


\section{1 - Infra-estrutura}

Para viabilização de um serviço de TMO é necessário uma infra-estrutura apropriada composta de setores específicos:

a - uma unidade de internação especializada com no mínimo duas enfermarias e espaços adicionais;

- enfermaria com: - área mínima de $9 \mathrm{~m}^{2}$, com paredes e piso de material resistente, lavável, passível de desinfecção, cantos arredondados, sem frestas, rachaduras ou orifícios, janela lacrada,

- leito ajustável,

- criado mudo ou pequeno armário,

- mesa auxiliar,

- cadeira,

- aparelho de televisão,

- bicos de saída de oxigênio, ar e vácuo centralizado,

- filtro-HEPA de parede,

- fluxo de ar laminar,

- pia e toalheiro preferentemente instalado a entrada da enfermaria e acionado por pedais,

- banheiro privativo cujas paredes, pisos e peças tenham as mesmas características da enfermaria,

- espaços adicionais: - secretaria e arquivos,

- sala para reuniões e contatos com familiares e visitas

- sala para descanso do pessoal com banheiros acoplados,

- espaço para descontaminação dos alimentos,

- posto de enfermagem,

- pias e toalheiros preferentemente acionados por pedais

e instalados em locais de fácil acesso ao pessoal,

- expurgo;

b - um serviço ambulatorial para acompanhamento do paciente durante as fases pré e pós-transplante com:

- consultório médico,

- posto de enfermagem,

- espaços para intervenções médicas e de enfermagem,

- banheiros,

- espaço para recepção,

- sala para reuniões da equipe e com paciente e familiares;

c - serviços complementares ao serviço de TMO:

- banco de sangue com capacidade para suporte hematológico do paciente com período prolongado além de três semanas, disponibilidade de elementos sanguíneos selecionados, capacidade para irradiação de hemoderivados, capacidade para lidar com incompatibilidade $\mathrm{ABO} / \mathrm{Rh}$,

- farmácia,

- laboratórios de imunologia, hematologia, microbiologia, patologia, com capacidade para tipagem HLA/CML, manipulação e crio-preservação da medula óssea,

- radiologia e radioterapia com capacidade para realizar ICT,

- nutrição com capacidade para descontaminação de alimentos,

- bloco cirúrgico,
- central de materiais,

- serviços de fisioterapia, odontologia, psicologia,

- serviço social,

- outros serviços comuns a toda instituição de saúde.

2 - Recursos humanos e operacionais

A viabilização de um serviço de TMO requer ainda recursos humanos e operacionais especializados:

a - para realização do TMO são necessários recursos humanos especializados, ou seja, equipe multiprofissional imunologista, oncologista, radiologista, epidemiologista, enfermeiro*, nutricionista, fisioterapeuta, psicólogo, odontólogo, assistente sociais, representantes dos laboratórios, do banco de sangue, da farmácia, agente administrativo;

* a equipe de enfermagem deve seguir preferentemente o modelo "Primary Nurse" de assistência e inclui:

- enfermeiro coordenador,

- enfermeiros assistenciais na proporção máxima de um enfermeiro para cada: dois pacientes,

- auxiliares de enfermagem;

b - para realização do TMO são necessários recursos operacionais que facilitem a assistência promovendo uma inter-relação e colaboração entre os recursos humanos e a racionalização da infra-estrutura, viabilizando o atendimento de pelo menos dois pacientes por vez e de 10 a 20 transplantes por ano; são recursos operacionais:

- plano geral de direcionamento do serviço, com filosofia claramente definida,

- definição de critérios para funcionamento do serviço,

- definição de critérios para avaliação da indicação do TMO,

- programas específicos para viabilização do serviço:

- programa de assistência na unidade de internação,

- programa de assistência ambulatorial,

- inter-relação com serviços complementares,

- programas de metas,

- programa administrativo,

- programa orçamentário,

- programa de treinamento / educação continuada / reciclagem e apoio.

3. Atuação do enfermeiro junto a serviços de TMO

A participação e assistência específicas que o enfermeiro presta ao paciente e familiares, dentro do trabalho da equipe multiprofissional do serviço de TMO, se dá em todas as fases do processo como se segue:

a - pré-admissão do paciente:

- confirmação do diagnóstico e avaliação do estágio atual da doença,

- avaliação geral do estado clínico atual do paciente,

- determinação do tipo de TMO adequado,

- avaliação das condições psico-emocionais e sócioeonômicas do paciente e família,

- avaliação de doadores potenciais e seleção do doador adequado, 
- fornecimento de informações completas, claras e inequívocas ao paciente, familiares e doador,

- processo de documentação do "consentimento informado" para o tratamento por parte do paciente, família e doador,

- participação na avaliação clínica geral do doador;

b - período de internação do paciente:

- estabelecimento de contato prévio com a enfermagem ambulatorial de TMO para obtenção de informações,

- orientação do paciente e família sobre as fases do tratamento (checagem das informações recebidas no ambulatório),

- orientação do paciente e família sobre a permanência em isolamento por período prolongado de tempo,

- orientação ao paciente e família sobre a estrutura e rotinas da unidade,

- instruções ao paciente sobre cuidados pessoais com relação a higiene, alimentação e lazer,

- esclarecimentos sobre os procedimentos que serão realizados,

- esclarecimentos sobre a identificação de sinais e sintomas esperados e os efeitos colaterais do tratamento,

- orientações a familiares sobre como proceder com relação a visitas ao paciente,

- implementação de rotinas de admissão ao paciente,

- coleta de material orgânico para pan-cultura,

- descontaminação da pele e trato gastro-intestinal,

- preparo do paciente para colocação do cateter atrial direito de longa permanência,

- implementação de cuidados na manutenção do cateter atrial direito,

- providências para o atendimento do paciente pelo serviço de nutrição e psicologia;

e - regime de condicionamento do paciente:

- administração de QT,

- acompanhamento na aplicação de ICT,

- implementação de cuidados de enfermagem quando houver manifestações de efeitos colaterais como: náuseas e vômitos, diarréia, mucosites, cistite hemorrágica, pancitopenia, desequilíbrio hidro-eletrolítico, reações

dermatológicas e alopecia;

d - TMO propriamente dito:

- atuação na coleta de medula óssea: - preparo préoperatório do doador (cuidados comuns a qualquer préoperatório),

- preparo da sala operatória e instrumentação cirúrgica,

- processamento imediato da medula óssea, auxilio na filtragem e acondicionamento da mesma,

- cuidados pós-operatórios do doador, com especial atenção para sinais de hemorragia e complicações hemodinâmicas ou cardiovasculares,

- cuidados na infusão da medula óssea no receptor:

- preparo da enfermaria com equipamento de cuidados críticos,

- preparo imediato do receptor para infusão da medula óssea através da verificação de sinais vitais e avaliação geral do paciente,

- administração da medula óssea no receptor por infusão pelo cateter central, com equipo sem filtro, no gotejamento próprio para cada tipo de TMO,

- em caso de TMO autólogo proceder ao descongelamento da medula óssea imediatamente antes da infusão,

- manter controles e observações durante a infusão da medula óssea através da verificação de sinais vitais,

observação de sinais de reações transfusionais, observação de sinais de distúrbios respiratórios;

e - período de enxertamento da medula óssea no receptor:

- manutenção dos cuidados de enfermagem direcionados à detecção de efeitos colaterais da QT e ICT,

- manutenção do controle de infecções com uso de técnicas rigorosamente assépticas, observação de sinais

e sintomas de infecções, administração profilática de antibiótico,

- manutenção do controle de hemorragias através da observação da presença de sangramento, do estado geral do paciente e administração de hemoderivados;

$\mathrm{f}$ - alta hospitalar planejada:

- confirmação do preenchimento dos critérios de alta hospitalar pós TMO,

- orientação ao paciente e família sobre a alta hospitalar, minimizando assim o estresse da mudança de ambiente,

- fornecimento de instruções escritas ao paciente e familiares sobre como proceder nos cuidados domiciliares para com o paciente numa linguagem clara e acessível, abordando:

- higiene pessoal e do ambiente,

- cuidados com a alimentação,

- orientações sobre evitar aglomerações humanas e contatos diretos com animais,

- cuidados com o cateter central,

- sinais e sintomas de complicações,

- retornos ao serviço ambulatorial de TMO,

- estabelecer contato com a enfermagem do serviço ambulatorial para fornecer informações sobre o paciente;

$\mathrm{g}$ - acompanhamento ambulatorial do paciente:

- manutenção das observações e controles para acompanhamento da recuperação do paciente $\mathrm{e}$ detecção precoce de sinais de complicações,

- implementação de cuidados de suporte: - administração de hemoderivados,

- acompanhamento e orientação sobre a nutrição domiciliária,

- observação de sinais e sintomas de infecção,

- administração de imunossupressores profiláticos de DEVH,

- viabilização do acompanhamento psicológico ambulatorial

- viabilização do acompanhamento ambulatorial por outros 
serviços da instituição quando necessário,

- viabilização da alta ambulatorial do paciente: encaminhamento do paciente ao serviço de saúde de origem para acompanhamento a longo prazo,

- orientação sobre a necessidade de retorno anual ao serviço de TMO;

h - complicações agudas do TMO:

- implementação de cuidados de enfermagem específicos quando houver complicações agudas:

- relacionadas ao regime de condicionamento,

- DEVH aguda,

- falência da medula enxertada e rejeição,

- infecções;

i - complicações crônicas do TMO:

- implementação de cuidados de enfermagem específicos quando houver manifestações de complicações crônicas:

- DEVH crônica,

- complicações pulmonares,

- complicações neuro-endócrinas, do crescimento de desenvolvimento,

- entidades mórbidas de caráter maligno secundárias ao TMO.

\section{CONCLUSÕES}

Ao término desse estudo, tendo presente 0 conteúdo da literatura pesquisada e levando em consideração, sobretudo os aspectos convergentes que predominaram nessa revisão e nossa própria experiência nesse campo de atuação da enfermagem concluímos que: - para viabilização de um serviço de TMO é necessária uma infra-estrutura apropriada composta de setores específicos: uma unidade de internação especializada e um setor ambulatorial onde o paciente e família possam receber a assistência adequada em cada fase de seu tratamento e uma infra-estrutura institucional que dê suporte a esse tratamento, com capacidade para atender ao menos dois pacientes concomitantemente, assegurando um mínimo de dez a vinte transplantes por ano;

- são necessários recursos operacionais, em termos de planejamento, que ajudem a viabilizar essa assistência promovendo uma inter-relação e colaboração entre os recursos humanos e o aproveitamento ótimo da infraestrutura. Dentro deste planejamento, devem estar previstos programas de formação de recursos humanos e educação continuada;

- são necessários recursos humanos especializados, capazes de prestar assistência adequada ao paciente levando em consideração o alto grau de complexidade do tratamento, e o enfermeiro, como membro dessa equipe multiprofissional, atuará em todas as fases do processo de tratamento, utilizando um modelo de assistência individualizada e integral, onde a relação máxima entre enfermeiro e paciente seja de um: dois respectivamente;

- o enfermeiro que atua em serviços de TMO deve ter uma formação especializada para ter competência em assistir o paciente em cada fase do tratamento, atentando para suas especificidades, sendo capaz de identificar as intercorrências próprias de cada uma delas e propor intervenções adequadas;

- o TMO representa um procedimento de nível terciário no âmbito da saúde; sendo de alta complexidade deve fazer parte do planejamento geral da instituição que o realiza;

- sendo um tratamento especializado, de alto custo e que atende a uma parcela limitada da população deve estar centralizado em instituições de referência regional ou mesmo nacional;

- os critérios para realização do transplante de medula devem estar claramente definidos e atender pressupostos éticos e filosóficos.

\section{CONTRIBUTION TO THE ORGANIZATION OF THE SERVICE OF BONE MARROW TRANSPLANTATION AND NURSE'S PERFORMANCE}

This is a bibliographic study on bone marrow transplantation emphasizing nurses actions, reviewed from publishings of the last ten years. The organization of informations allowed authors to identify that for performing a transplant it would be necessary to have an adequate infrastructure, specialized human resources and operational resources for the assistance to be feasible. It was determined that nurses actions in this procedure are required in all stages of care, differently in each phase, and preferentiality individualized and integral in a maximum ratio of one nurse for two patients.

\section{CONTRIBUCIÓN A LA ORGANIZACIÓN DE SERVICIOS DE TRANSPLANTE DE MEDULA ÓSEA Y LA ACTUACIÓN DEL ENFERMERO}

Es un estudio bibliográfico sobre la temática: transplante de medula ósea con énfasis en la actuación del enfermero, levantada en publicaciones de enfermería en los últimos diez años. Las informaciones organizadas y sistematizadas permitieron 
identificar que para la realización del transplante es necesaria una infra-estructura apropiada, recursos humanos especializados y recursos operacionales que viabilicen la asistencia. Fue posible identificar también que la actuación del enfermero en ese procedimiento se da en todas las fases del proceso de asistencia al paciente, de manera peculiar en cada una de ellas, preferentemente de manera individualizada e integral, en la proporción máxima de un enfermero para dos pacientes.

TÉRMINOS CLAVES: transplante de la medula ósea, asistencia de enfermería

\section{REFERÊNCIAS BIBLIOGRÁFICAS}

01. CORCORAN-BUCHSEL, P.; KELLEHER, J. Bone marrow transplantation. Nurs.Clin.of North Am., v. 24, n. 4, p. 907-938, December 1989.

02. DEEG, H.J.; KLINGEMANN, H.G.; PHILLIPS, G.L. A guide to bone marrow transplantation. 2.ed. New York, Springer-Verlag, 1992. 309 p.

03.DULLEY, F. L. et al. Etiopatogênese da anemia aplástica e tratamento da forma severa com imunossupressão e transplante de medula óssea. Rev.Hosp.Clin.Fac.Med.Univ.São Paulo, v. 44, n. 4, p. 167-170, jul./ago. 1989.

04. PASQUINI, R.; FERREIRA, E. Transplante de medula óssea. In: OLIVEIRA, H.P. et al. Hematologia clínica. 3.ed. Rio de Janeiro: Atheneu, 1985. cap. 25, p. 561-577.

\section{BIBLIOGRAFIA CONSULTADA}

01. AMERICAN SOCIETY OF CLINICAL ONCOLOGY. The American Society of Clinical Oncology and American Society of Hematology recommended criteria for the performance of bone marrow transplantation. Journal of Clinical Oncology, v. 8, n. 3, p. 563-564, March 1990.

02. BORLEY, D. Questioning and adapting. Nursing Mirror, v. 160, n. 6, p. 30-34, 1985.

03. BRACK, G.; La CLAVE, L.; BLIX, S. The psychological aspects of bone marrow transplant. Cancer Nursing, v. 11, n. 4, p. 22 1-229, 1988.

04. BRANDWEIN, J.M. et al. An evaluation of out patient bone marrow harvesting. Journal of Clinical Oncology, v. 7, n. 5, p. 648-650, May 1989.

05. CAMP-SORRELL, D.; GRAHAM, C. Reducing costs the ancillary way. Oncology Nursing Forum, v. 18, n.7, p. 1246-1247, 1991.

06. CARNEY, B. Bone marrow transplantation: nurses' and physicians' perceptions of informed consent. Cancer Nursing, v. 10, n. 5, p. 252-259, 1987.

07. CHIELENS, D.; HERRICK, E. Recipients of bone marrow transplants: making a smooth transition to an ambulatory care setting. Oncology Nursing Forum, v. 17, n. 6, p. 857-862, 1990.
08. COGLIANO-SHUTTA, N. A.; BRODA, E. J.; GRESS, J.S. Bone marrow transplantation: overview and comparison of autologous, syngeneic, and allogeneic treatment modalities. Nursing Clinics of North America, v. 20, n. 1, p. 49-66, March 1985.

09. COLLINS, C.; UPRIGHT, C.; ALEKSICH, J. Reverse isolation: what patients perceive. Oncology Nursing Forum, v. 16, n. 5, p. 675-679, Sep./Oct. 1989.

10. COPEL, L.C.; SMITH, M.E. Oncology nurse's knowledge of graft-versus-host disease in bone marrow transplant patients. Cancer Nursing, v. 12, n. 4, p. 243-249, 1989.

11. CORCORAN-BUCHSEL, P.; PARCHEM, C. Ambulatory care of the bone marrow transplant patient. Seminars in Oncology Nursing, v. 4, n. 1, p. 41-46, 1988.

12. CORCORAN-BUCHSEL, P.; KELLEHER, J. Bone marrow transplantation. Nursing Clinics of North America, v. 24, n. 4, p. 907-938, December 1989.

13. DEEG, H.J.; KLINGEMANN, H.G.; PHILLIPS, G.L. A guide to bone marrow transplantation. 2.ed. New York, Springer-Verlag, 1992. 309p.

14. DULLEY, F.L. et al. Etiopatogênese da anemia aplástica e tratamento da forma severa com imunossupressão e transplante de medula óssea. Rev. Hosp. Clin. Fac. Med. Univ. São Paulo, v. 44, n. 4, p. 167-170,jul./ago. 1989.

15. FORD, R.; BALLARD, B. Acute complications after bone marrow transplantation. Seminars in Oncology Nursing, v. 4, n. 1, p. 15-24, 1988.

16. FORD, R.; EISENBERG, S. Bone marrow transplantation - recent advances and nursing implications. Nursing Clinics of North America, v. 25, n. 2, p. 405-422, June 1990.

17. HOLCOMBE, A. Bone marrow harvest. Oncology Nursing Forum, v. 14, n. 2, p. 63-65, Mar./Apr. 1987.

18. HOLMES, W. Preparing the patient for bone marrow transplantation: nursing care issues. The Yale Journal of Biology and Medicine, v. 63, n. 5, p. 487-494, 1990.

19. HUTCHISON, M.M.; KING, A.H. A nursing perspective on bone marrow transplantation. Nursing Clinics of North America, v. 18, n. 3 , p. 511-522, Sept. 1983. 
20. KALIL, I.; NEUMANN, J. Imunologia de transplantes. In: CALICH,V.L.G.;VAZ,C.A.P. Imunologia básica. Porto Alegre: Artes Médicas, 1989. cap. 15, p. 294-307.

21. KELLEHER, J.; JENNINGS, M. Nursing management of marrow transplant unit: a framework for practice. Seminars in Oncology Nursing, v. 4, n. 1, p. 60-68, 1988.

22. KELLEHER, J. Issues for designing marrow transplant programs. Seminars in Oncology Nursing, v. 10, n. 1, p. 64-71, 1994.

23. LARSON, P.J. et al. Comparison of perceived symptoms of patients undergoing bone marrow transplant and the nurses caring for them. Oncology Nursing Forum, v. 20, n. 1, p. 81-87, 1993.

24. LINDGREN, P.S. The laminar air flow room nursing practices and procedures. Nursing Clínics of North America, v. 18, n. 3, p. 553561,Sept. 1983.

25. MAHMOUD, H.K. et al. Laminar air flow versus barrier nursing in marrow transplant recipients. Blut, v. 49, n. 5, p. 375-381, 1984.

26.MAULDIN, B.C. Harvest of hope: bone marrow transplantation. AORN Journal, v. 36, n. 3, p. 385-390, Sept. 1982.

27. McCONN, R. Skin changes following bone marrow transplantation. Cancer Nursing, v. 10, n. 2, p. 82-84, 1987.

28. NIMS, J.W.; STROM, S. Late complications of bone marrow transplantation recipients: nursing care issues. Seminars in Oncology Nursing, v. 4, n. 1, p. 47-54, 1988.

29. NUSCHER, R. et al. Bone marrow transplantation - a life saving option. American Journal of Nursing, v. 84, n. 6, p. 764-772, Jun. 1984.

30 - PASQUINI, R.; FERREIRA, E. Transplante de medula óssea. In: OLIVEIRA, H.P. et al. Hematologia clínica. 3.ed. Rio de Janeiro:
Atheneu, 1985. cap. 25, p. 56 1-577.

31. POLIQUIN, C.M. Post - bone marrow transplant patient management. The Yale Journal of Biology and Medicine, v. 63, n. 5, p. 495502, 1990.

32. RAPAPORT, S. I. Introdução à hematologia. 2.ed. São Paulo: Roca, 1990, 450 p.

33. ROZMAN, C. Transplante de medula óssea. Rev.Hosp.Clin.Fac.Med.Univ.São Paulo, v. 40, n. 3, p. 125-140, maio/jun. 1985.

34. SALVADOR, A.D. Métodos e técnicas de pesquisa bibliográfica. 11 .ed. Porto Alegre: Sulina, 1986.

35. SCHRYBER, S.; LACASSE, C.R.; BARTONBURKE, M. Autologous bone marrow transplantation. Oncology Nursing Forum, v. 14, n. 4, p. 74-79, 1987.

36. STEWART, F.M. et al. Bone marrow transplantation - three treatments for disease. AORN Journal, v.42, n. 2, p. 169-2I1,August 1985.

37. TABAK, D.G. Transplante de medula óssea. In: SCHWARTSMANN, G. et al. Oncologia clínica: princípios e prática. Porto Alegre: Artes Médicas, 1991. cap. 15, p. 171-180.

38. TOYONAGA, E.T. et al. Complicações no uso de cateteres venosos centrais de longa permanência em transplante de medula óssea. Rev.Paul.Enfermagem, v. 8, n. 2, p. 23-28, 1988.

39. TSUNECHIRO, M.A. et ai. Instrumento para análise de periódico de enfermagem. Rev.Esc.Enfermagem USP, v. 17, n. 2, p. 107-117, 1983.

40. VRIES, E.G.E.; SLEIJFER, D.T.; MULDER, D.H. Outpatient bone marrow harvesting without general anesthesia. Journal of Clinical Oncology, v. 7, n. 9, p. 1367-1368, Sept. 1989. 
ANEXO 1

\section{Representação esquemática do processo de TMO}

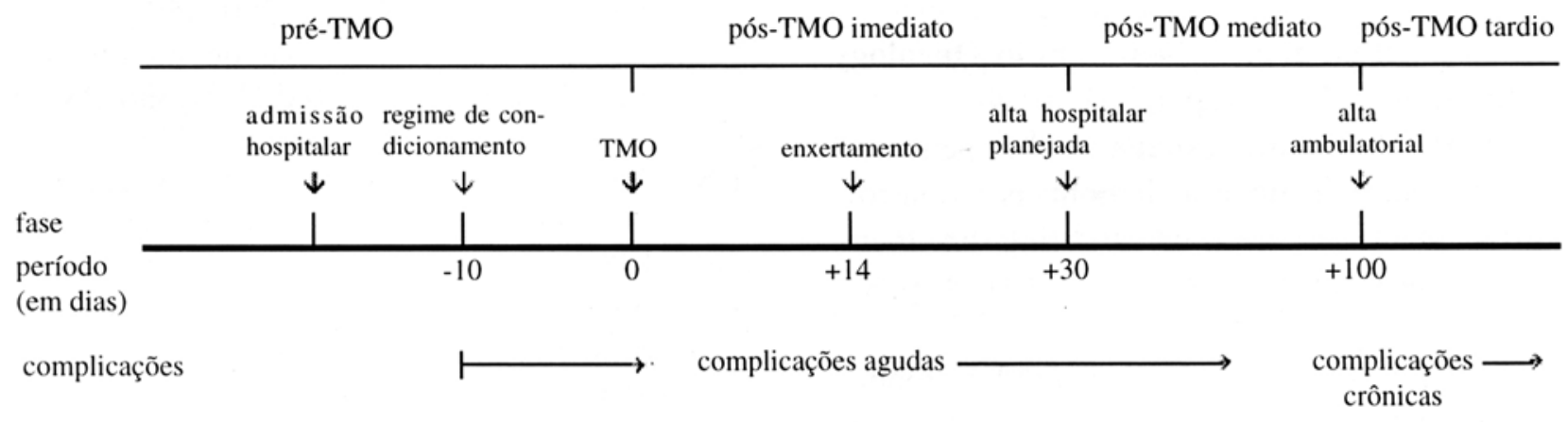

